Check for updates

Cite this: RSC Adv., 2017, 7, 48537

\title{
Lignin-derived carbon nanosheets for high-capacitance supercapacitors
}

\author{
Wanshuang Liu, (D) *a Yimin Yao, ${ }^{a}$ Ouli Fu, ${ }^{a}$ Sihan Jiang, ${ }^{a}$ Yucheng Fang, ${ }^{a}$ Yi Wei ${ }^{a}$ \\ and Xuehong Lu (DD ${ }^{b}$
}

Lignin, a type of abundant and low-cost biomass, is successfully utilized as a carbon precursor to prepare carbon nanosheets (CNSs) by freeze-casting of a lignin aqueous dispersion followed by direct carbonization without any activating treatment. The size and specific area of the obtained lignin-derived CNSs can be manipulated by controlling the concentrations of lignin aqueous dispersions, which in turn influences the graphitization degree of the CNSs as confirmed by wide angle X-ray scattering analysis and Raman spectroscopy. X-ray photoelectron spectroscopy study indicates that the CNSs contain $~ 11-16$ at\% oxygen heteroatoms, which contribute to additional pseudocapacitance. The three-electrode supercapacitors based on optimized CNSs show a high capacitance of $281 \mathrm{~F} \mathrm{~g}^{-1}$ at $0.5 \mathrm{~A} \mathrm{~g}^{-1}$ current density and good cycling stability in $\mathrm{H}_{2} \mathrm{SO}_{4}$ aqueous electrolyte. The study provides a simple, inexpensive, and environmentally friendly method for preparation of CNSs from various water-soluble biomass carbon precursors.

Received 2nd August 2017

Accepted 10th October 2017

DOI: 10.1039/c7ra08531a

rsc.li/rsc-advances

\section{Introduction}

Due to climate change and environmental problems brought by the growing global energy consumption, development of sustainable, environment-friendly and efficient energy conversion and storage systems is of great importance. Supercapacitors (also called electrochemical capacitors), a category of electrical energy storage devices, have drawn intense attention owing to their high power density, long cycle life and rapid charging processes..$^{1-4}$ As a means of power supply, supercapacitors have great potential for a wide range of applications, including hybrid electric vehicles, wind turbines, wearable electronic devices, and power management. ${ }^{5-8}$ Based on their energy storage mechanisms, supercapacitors can be classified into two categories: electrical double layer capacitors and pseudo-capacitors. ${ }^{9}$ Currently, the commercial electrode materials for supercapacitors are primarily based on activated carbons because of their low cost and good electrochemical stability. Such carbon electrodes typically exhibit much higher electrostatic double-layer capacitance than electrochemical pseudocapacitance. However, most of the conventional activated carbons are produced from the fossil and coal resources, facing many challenges due to the non-sustainable availability of carbon precursors. Recently, extensive research efforts have been made to produce various activated or porous carbonaceous materials from renewable low-cost biomass such as

${ }^{a}$ Donghua University Center for Civil Aviation Composites, Donghua University, 2999 North Renmin Road, Shanghai, 201620, China. E-mail: wsliu@dhu.edu.cn

${ }^{b}$ School of Materials Science and Engineering, Nanyang Technological University, 50 Nanyang Avenue, Singapore 639798, Singapore chitosan,${ }^{10}$ lignin, ${ }^{11,12}$ cellulose,${ }^{13}$ hemp,${ }^{14}$ eggshell, ${ }^{15}$ seaweeds, ${ }^{7}$ silk proteins ${ }^{16}$ and pine cone. ${ }^{17}$

Lignin, which comprises up to 20 to $30 \%$ weight of woody plants, is the second most abundant natural polymer after cellulose and the most dominant aromatic polymer on earth. ${ }^{18,19}$ It is estimated that the annual production volume of lignin in pulp and paper industry is about 70 million tons globally. ${ }^{20}$ In the past decade, lignin has been extensively explored for value-added applications. For example, in our previous studies, lignin has been successfully used as macromolecular toughening agent for epoxy resin ${ }^{21}$ and surfactant for two-dimension nano-materials such as graphene ${ }^{22}$ and molybdenum disulfide. ${ }^{23}$ Lignin can also be regarded as an ideal carbon precursor due to its low cost and bituminous coal-like structure. ${ }^{24}$ Very recently, Zhang and Zhao prepared threedimensional porous carbon by carbonization of lignin using $\mathrm{KOH}$ as activating agent and template. ${ }^{11}$ This porous carbon was used as electrode materials for supercapacitors and showed high stability and good rate performance. Jeon and Nune reported that nanoporous carbon with controlled porosity can be prepared by direct carbonization of lignin with different molecular weight. ${ }^{12}$ The supercapacitors based on this nanoporous carbon exhibited high energy density and excellent cycling stability. In these reported work, the morphology of the lignin-derived carbons were textured by adding activating agent during carbonization or altering the types of lignin, while the effects of lignin precursor morphology before carbonization was seldom taken into account.

Freeze casting (also called ice templating), which is a relatively simple and inexpensive technology, has been used to produce layered ceramic scaffolds for biomimetic materials. ${ }^{25,26}$ 
In this process, the ceramic aqueous suspensions are treated by directional freeze, and the ceramic particles are entrapped within channels between the ice crystals. After sublimation of the water, a negative replica of the lamellar ice crystals is formed. Inspired by these ceramic ice templating processes, in this work, two dimensional lignin sheets were prepared by freeze-dying liquid-nitrogen-quenched lignin dispersion. The lignin sheets were then used as carbon precursor to produce carbon nanosheets (CNSs) by direct carbonization without any activation treatment. The morphology of the obtained CNSs can be controlled by adjusting the concentrations of lignin aqueous dispersions. Herein we demonstrate that the CNSs from renewable lignin show good electronic conductivity and excellent electrochemical performance as supercapacitor electrodes in an aqueous electrolyte.

\section{Experimental}

\section{Material preparation}

Water-soluble alkali lignin (softwood lignin L0082, TCI America, USA) was directly used to prepare CNSs without further purification. A desired amount of lignin (100, 200, $400 \mathrm{mg}$ ) was added to $20 \mathrm{~mL}$ Millipore water in a glass bottles. When alkali lignin was completely dispersed after 10 minute bath ultrasonic treatment, the resulting lignin dispersion was immersed in liquid nitrogen. The frozen sample was freeze-dried (BenchTop Manifold Freeze Dryer, Millrock Technology, Inc.) for $48 \mathrm{~h}$ to give fluffy light brown lignin powder. The lignin powder was placed in a ceramic crucible and then transferred to a furnace. The furnace was tightly sealed and purged with argon gas. Initially the temperature was increased to $100{ }^{\circ} \mathrm{C}$ at a rate of $5{ }^{\circ} \mathrm{C} \min ^{-1}$ for $2 \mathrm{~h}$ to remove oxygen and moisture residual in the furnace. The temperature was further increased to $900{ }^{\circ} \mathrm{C}$ at a rate of $2{ }^{\circ} \mathrm{C} \min ^{-1}$, and maintained at $900{ }^{\circ} \mathrm{C}$ for six hours in the argon atmosphere to carbonize the lignin. After carbonization, the furnace was naturally cool down to room temperature in presence of argon, and a black carbon powder was obtained.

\section{Characterization}

The composition of CNSs was measured by X-ray photoelectron spectroscopy (XPS, Kratos Analytical AXIS His spectrometer). A monochromatized $\mathrm{Al} \mathrm{K} \alpha \mathrm{X}$-ray source at $1486.6 \mathrm{eV}$ was adopted to scan the surfaces of CNSs. Raman spectroscopy was performed on a Renishaw In via Raman microscope and the excitation wavelength was $633 \mathrm{~nm}$. Wide angle X-ray scattering (WAXS) analysis for CNSs was investigated by a Bruker D8 Advanced XRD with $\mathrm{Cu} \mathrm{K} \alpha 1$ radiation source. Brunauer-Emmet-Teller (BET) surface area was calculated from the nitrogen isotherm curves measured on a nitrogen adsorption device (Micromeritics Tristar II-3020) at $77 \mathrm{~K}$. The pore size distribution was calculated by density functional theory (DFT) method. The electrical conductivity of CNSs powders was tested by a four probe method (CMTSR2000N, Advanced Instrument Technology) using a pellet sample prepared by pressing under $10 \mathrm{MPa}$ fixed pressure. ${ }^{27}$ The CNS morphologies were observed by field emission scanning electron microscope (JEOL FESEM 7600F).

\section{Electrode preparation-electrochemical tests}

Three-electrode systems were assembled to study the electrochemical performances of lignin-derived CNSs on PGSTAT30 Autolab potentiostat. Pt plate and $\mathrm{Ag} / \mathrm{AgCl}$ were used as counter electrode and the reference, respectively. The working electrode was fabricated through mixing $95 \mathrm{wt} \%$ CNSs and $5 \mathrm{wt} \%$ polyvinylidene fluoride (PVDF) in $N$-methyl-2-pyrrolidinone (mPVDF $:$ mNMP $=2: 98$ ). The black mixture was magnetically stirred for $12 \mathrm{~h}$ and the obtained slurry was coated on graphite paper $\left(1 \times 1 \mathrm{~cm}^{2}\right)$. The electrode was then dried at $60{ }^{\circ} \mathrm{C}$ under vacuum. The loading mass of each electrode is about $1 \mathrm{mg}$. Cyclic voltammetry (CV) and galvanostatic charge/ discharge (GCD) measurements were conducted using $1 \mathrm{M}$ $\mathrm{H}_{2} \mathrm{SO}_{4}$ aqueous electrolyte in the voltage range of $-0.1-0.9 \mathrm{~V}$. The electrochemical impedance spectroscopy (EIS) tests were conducted to investigate the impedance characteristics of CNSs using AC voltage with $5 \mathrm{mV}$ amplitude in the frequency range of 0.01-100 kHz under open circuit voltage. Two-electrode systems were assembled by the similar procedure using the same mass loading in the positive and the negative electrodes. A polyethylene (PE) diaphragm was placed between the two electrodes. The potential window for the two-electrode systems was $0-1.0 \mathrm{~V}$.

\section{Results and discussion}

\section{Preparation and morphology of lignin-derived carbon}

Lignin contains a large amount of aromatic structure (Fig. 1) and hence is an excellent carbon precursor. The preparation process of lignin-derived carbon is illustrated in Fig. 1. Tyndall effect was observed from lignin aqueous dispersion, indicating that it is colloid system. During quick quench of the lignin aqueous dispersion by liquid nitrogen, ice crystals can act as laminar templates. In as-received lignin powder sample, most particles show near-spherical morphology and have a diameter from a few micrometers to many tens micrometers (Fig. 2a). After freeze-casting treatment, the morphology of lignin was converted to sheet-like and the size of the lignin sheets distinctly increases with increasing the concentration of the lignin dispersion (Fig. 2b-d). After carbonization at $900{ }^{\circ} \mathrm{C}$, the as-received lignin was converted to closely stacked nearspherical carbon particles (Fig. 2e). For the lignin sheets obtained by freeze-casting, the sheet morphology was well retained after carbonization (Fig. 2f-h). Like their lignin precursor, the size and stacking compactness of the obtained lignin carbon sheets increase with the increase in concentration of the lignin dispersion. To easily identify the thickness of these corrugated carbon sheets, the sample prepared from $5 \mathrm{mg} \mathrm{mL}^{-1}$ lignin dispersion was dispersed in water and broken by ultrasonic treatment (Sonic \& Materials model VCX-750 with $1 \mathrm{~cm}^{2} \mathrm{Ti}$ horn). The representative SEM images of the broken carbon sheets are shown in Fig. 3. Based on the statistics of a large amount of specimens, the thickness of these lignin-derived carbon sheets mainly lies in the range of 50-150 nm. Therefore, this study provides a simple and environmentally friendly method to produce lignin-derived CNSs. 

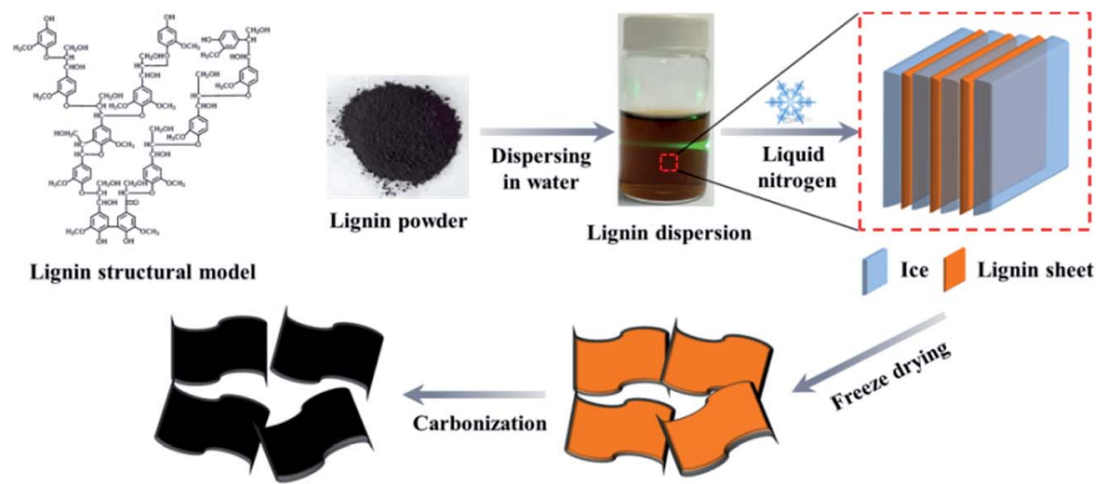

Carbonization

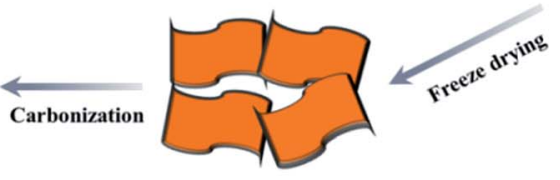

Lignin sheets

Fig. 1 Lignin structure model and schematic illustration of preparation process of lignin-derived carbon through freeze-casting method.

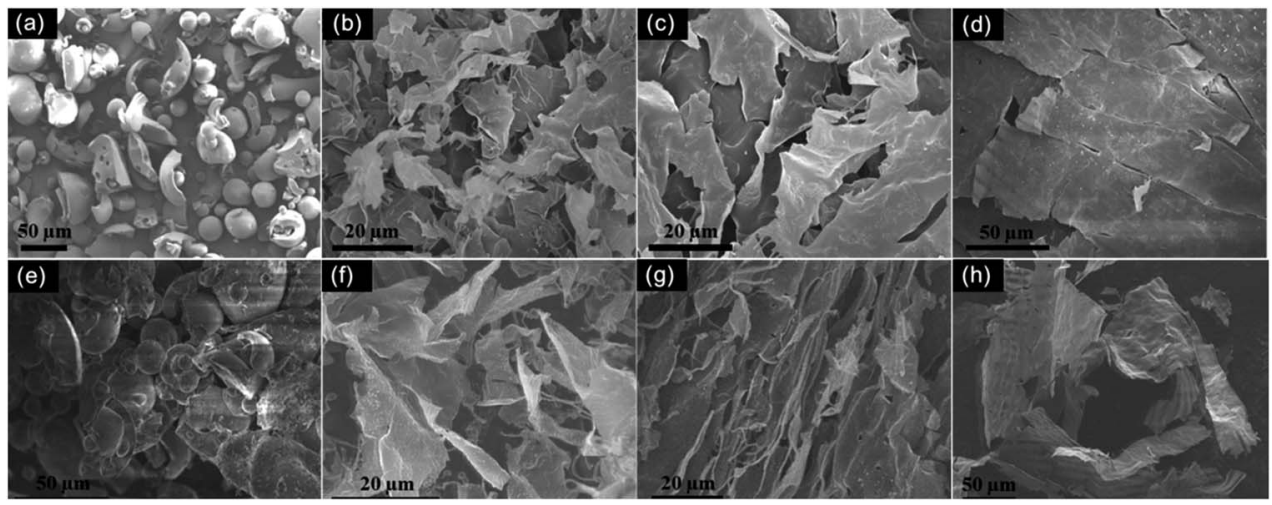

Fig. 2 SEM images of as-received lignin powders (a) and lignin sheets prepared from 5 (b), 10 (c), 20 (d) $\mathrm{mg} \mathrm{mL}^{-1}$ lignin aqueous dispersions by freeze-casting method; SEM images of lignin-derived carbon prepared from carbonization of as-received lignin powders (e) and lignin sheets obtained by freeze-casting of 5 (f), 10 (g), 20 (h) $\mathrm{mg} \mathrm{mL}^{-1}$ lignin aqueous dispersions.

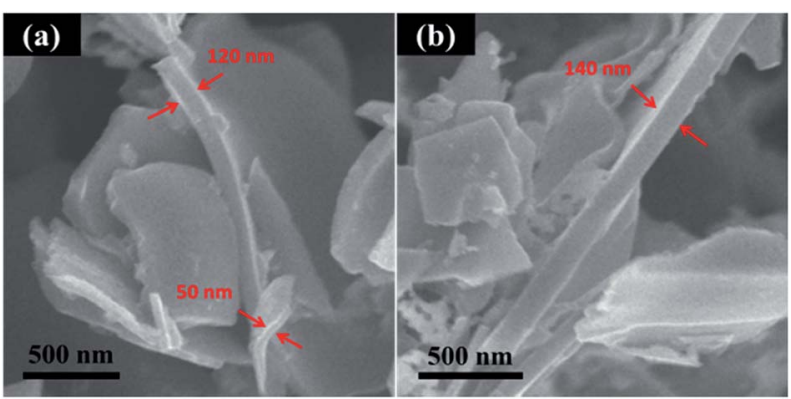

Fig. 3 SEM images of the cross section of broken carbon sheets prepared from $5 \mathrm{mg} \mathrm{mL}^{-1}$ lignin aqueous dispersion.

\section{Composition and properties of lignin-derived CNSs}

The graphitic degree of lignin-derived CNSs was investigated by Raman spectroscopy (Fig. 4a). The CNSs prepared from 5, 10 and $20 \mathrm{mg} \mathrm{mL}^{-1}$ lignin aqueous dispersions are abbreviated as LC-05, LC-10 and LC-20, respectively. The Raman spectra of all the three CNS samples show two peaks associated with D band $\left(\sim 1360 \mathrm{~cm}^{-1}\right)$ and $\mathrm{G}$ band $\left(\sim 1600 \mathrm{~cm}^{-1}\right)$, respectively. The D band signal can be ascribed to the $\mathrm{A}_{1 \mathrm{~g}}$ phonon breathing vibrations from disordered carbon, and the $\mathrm{G}$ band single is related to the $\mathrm{E}_{2 \mathrm{~b}}$ mode of phonon vibrations from graphitic $\mathrm{sp}^{2}$ hybridized carbon. ${ }^{27}$ The intensity ratios of the $\mathrm{G}$ band to $\mathrm{D}$ band $\left(I_{\mathrm{G}} / I_{\mathrm{D}}\right)$ can reflect the graphitic degree of the three types of CNS samples. The results in Fig. 4a show that the graphitic degree of CNSs decreases with increasing the concentration of lignin precursor dispersion, presumably because thinner lignin sheets facilitate easier removal of volatile products during carbonization.

To further determine the chemical composition and valence state of carbon atoms, the three types of CNS samples was investigated by XPS (Fig. $4 \mathrm{~b}$ and Table 1). The results of XPS measurement give the atom ratio of different elements in the prepared CNSs. Interestingly, the oxygen content in the CNSs shows continuous increase with increasing the concentration of lignin precursor dispersion. LC-05, LC-10 and LC-20 CNSs contain 11.1, 12.4 and 15.8 at\% oxygen, respectively. This result may be because the increased size and stack compactness of lignin precursor sheets as the increase in lignin dispersion concentrations (Fig. 2b-d) restrain the generation of oxygencontaining volatile products during the carbonization. Although the residual oxygen-containing groups inevitably reduce the conductivity of prepared CNSs to some extent, they will contribute to improve the wettability of the carbon 

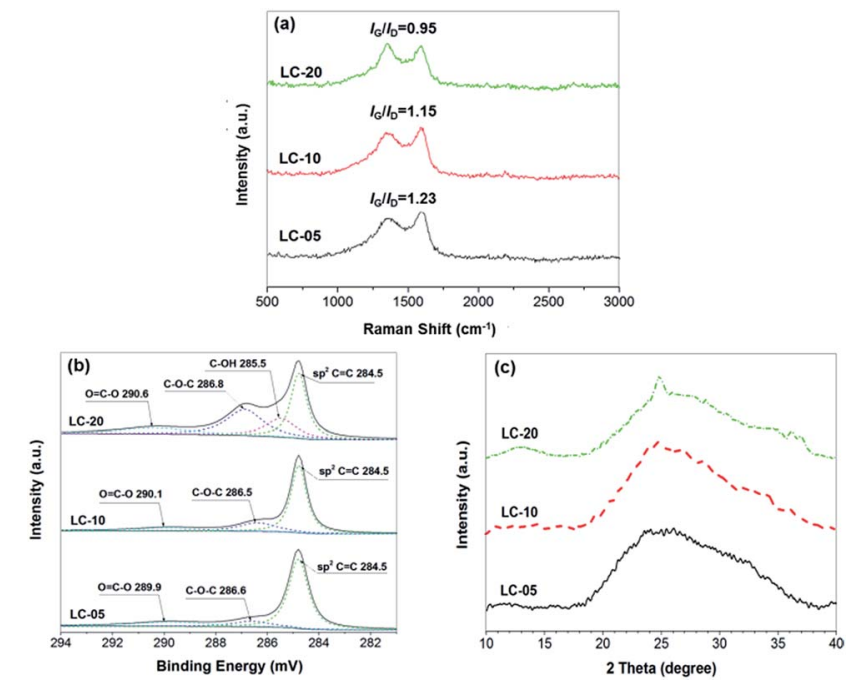

Fig. 4 Raman spectra (a), deconvulated C 1s XPS spectra (b) and WAXS patterns (c) of LC-05, LC-10 and LC-20, respectively.

electrodes with aqueous electrolytes and provide pseudocapacitance. $^{28,29}$ The deconvoluted C 1s spectra of the three CNS samples (Fig. 4b) show a main peak at $284.8 \mathrm{eV}$ assigned to $\mathrm{sp}^{2}$ $\mathrm{C}=\mathrm{C}$ and several weak peaks at 285.5, 286.5 and $290.1 \mathrm{eV}$, which can be assigned to the carbon in $\mathrm{C}-\mathrm{OH}, \mathrm{C}-\mathrm{O}-\mathrm{C}$, and $\mathrm{O}=$ $\mathrm{C}-\mathrm{O}$, respectively. ${ }^{30}$ Among them, LC-20 shows the highest content of non-graphitic carbon, which is consistent with the data of Raman spectroscopy. The structures of three CNS samples were also investigated by WAXS (Fig. 4c). As can be seen, all the CNSs show a quite broad peak around $2 \theta=25^{\circ}(d=$ $\sim 0.4 \mathrm{~nm}$ ), indicating the $\mathrm{sp}^{2}$ hybridized carbon domains do not exhibit long-range order. It should be noted that a weak and broad peak appeared around $2 \theta=13^{\circ}(d=\sim 0.7 \mathrm{~nm})$ in the spectrum of LC-20, which may be due to the existence of more oxygen-containing groups between the carbon phase.

Nitrogen adsorption isotherms at $77 \mathrm{~K}$ and the pore size distribution curves of three CNS samples are shown in Fig. 5 and the data are summarized in Table 1. As expected, LC-05 shows the highest BET specific surface area $\left(\mathrm{SSA}_{\mathrm{BET}}=\right.$ $\left.854.7 \mathrm{~m}^{2} \mathrm{~g}^{-1}\right)$ compared with LC-10 $\left(287.7 \mathrm{~m}^{2} \mathrm{~g}^{-1}\right)$ and LC-20 $\left(96.5 \mathrm{~m}^{2} \mathrm{~g}^{-1}\right)$. Besides the specific surface area, the porosity and pore size distribution also play important roles to determine the energy storage capabilities of the lignin-derived CNSs. The pore size distributions (Fig. 5b) indicate three ligninderived CNSs possess mainly micropores (pore width $<2 \mathrm{~nm}$ ). The formation of micropores may be because the gas (such as $\mathrm{CO}_{2}$ and $\mathrm{H}_{2} \mathrm{O}$ ) genetated during lignin pyrolysis could act as (a)

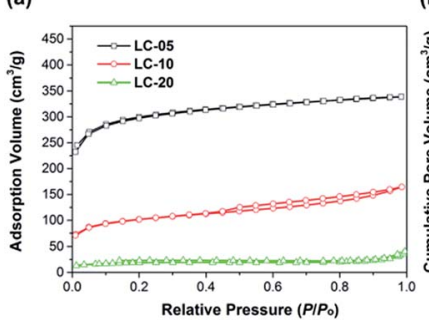

(b)

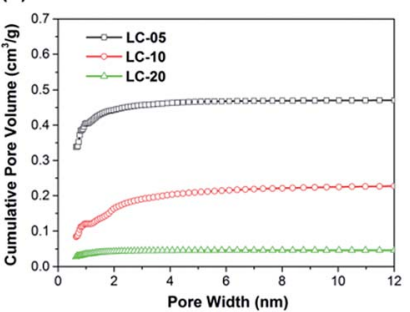

Fig. 5 Nitrogen adsorption isotherms at $77 \mathrm{~K}(\mathrm{a})$ and pore size distribution curves calculated by DFT method (b) of LC-05, LC-10 and LC20 , respectively.

internal physical activation agents. ${ }^{12}$ These micropores would lead to enhanced specific capacitance because of the smaller charge separation distance between the ion centers and the pore walls. ${ }^{31}$ The results of four-probe tests show that the electrical conductivities of LC-05, LC-10 and LC-20 powder samples are $2.5,1.9$ and $1.1 \mathrm{~S} \mathrm{~cm}^{-1}$, respectively. As expected, the trend of conductivity is opposite to the trend for the content of oxygen impurities in CNSs. The conductivity of LC-05 is comparable to that of the CNSs prepared from hemp (2.1-2.3 $\left.\mathrm{S} \mathrm{cm}^{-1}\right)$ and lower than that of commercial graphene nanoplatelets $\left(2.9 \mathrm{~S} \mathrm{~cm}^{-1}\right) \cdot{ }^{14}$

\section{Supercapacitors from lignin-derived CNSs}

To evaluate the electrochemical performance of the ligninderived CNSs, LC-05, LC-10 and LC-20 were applied as electrode materials for a three-electrode configuration system in $1 \mathrm{M} \mathrm{H}_{2} \mathrm{SO}_{4}$ aqueous electrolyte without addition of any conductive additives. Fig. 6a presents the representative cyclic voltammetry (CV) curves of the three CNS samples between $-0.1-0.9 \mathrm{~V}$ at scan rate of $5 \mathrm{mV} \mathrm{s}^{-1}$. In principle, the $\mathrm{CV}$ curve for an ideal activated carbon electrode shows a nearly rectangular shape. The humps in the CV curves of the three CNS samples can be attributed to the pseudocapacitance contribution from the oxygen heteroatom. ${ }^{11,28}$ The mechanism of faradaic processes caused by oxygen-containing groups can generally be attributed to the reversible redox reactions as shown in the following equations: ${ }^{32}$

$$
\begin{gathered}
\text { Phenolic: }>\mathrm{C}-\mathrm{OH} \leftrightarrow \mathrm{C}=\mathrm{O}+\mathrm{H}^{+}+\mathrm{e}^{-} \\
\text {Ketone: }>\mathrm{C}=\mathrm{O}+\mathrm{e}^{-} \leftrightarrow \mathrm{C}-\mathrm{O}^{-} \\
\text {Carboxylic: }-\mathrm{COOH} \leftrightarrow-\mathrm{COO}^{-}+\mathrm{H}^{+}+\mathrm{e}^{-}
\end{gathered}
$$

Table 1 Composition and properties of lignin-derived CNSs

\begin{tabular}{lllllll}
\hline Sample & $\mathrm{C}(\mathrm{at} \%)$ & $\mathrm{O}(\mathrm{at} \%)$ & $\mathrm{N}(\mathrm{at} \%)$ & $\mathrm{S}(\mathrm{at} \%)$ & $\mathrm{SSA}_{\mathrm{BET}}\left(\mathrm{m}^{2} \mathrm{~g}^{-1}\right)$ & $\mathrm{Conductivity}\left(\mathrm{S} \mathrm{cm}^{-1}\right)$ \\
\hline LC-05 & 88.4 & 11.1 & - & 0.5 & 854.7 & 2.5 \\
LC-10 & 86.8 & 12.4 & - & 0.8 & 287.7 & 1.9 \\
LC-20 & 82.9 & 15.8 & - & 1.3 & 96.5 & 1.1
\end{tabular}


(a)

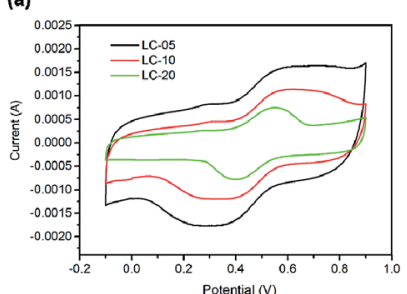

(c)

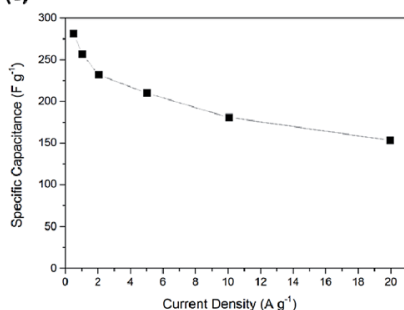

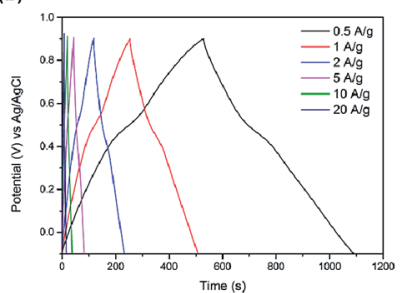

(d)

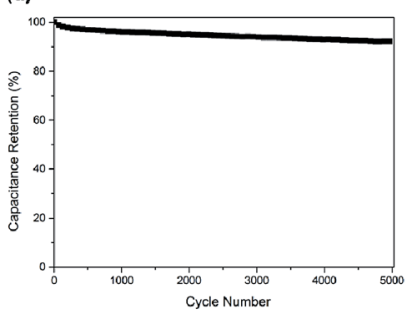

Fig. 6 Electrochemical performances of lignin-derived CNSs. (a) CV curves of LC-05, LC-10 and LC-20 at scan rate of $5 \mathrm{mV} \mathrm{s}^{-1}$ in $1 \mathrm{M}$ $\mathrm{H}_{2} \mathrm{SO}_{4}$; (b) galvanostatic charge-discharge curves of LC-05 at different current rates; (c) the rate performance of LC-05; (d) the capacitance retention of $\mathrm{LC}-05$ versus cycle number at current density of $1.0 \mathrm{~A} \mathrm{~g}^{-1}$.

According to the deconvoluted C 1s XPS spectra of three CNSs (Fig. 4b), the pseudocapacitance for LC-05 and LC-10 samples was mainly contributed by carboxylic groups, while the pseudocapacitance for LC-20 sample was contributed by carboxylic and phenolic groups. Fig. 6a shows that the CV curve of LC-05 has the highest area compared with LC-10 and LC-20, indicating a superior capacitive property. This is due to the highest specific area and conductivity of LC-05. Although LC-20 has the highest oxygen content, its capacitive property is the lowest due to the low graphitization degree and specific area. Fig. $6 \mathrm{~b}$ shows the GCD curves of LC-05 at different current rates. These charge-discharge curves show a symmetrical quasitriangle shape, suggesting the reversible capacitive behaviours of LC-05 in the acid electrolyte. According to the GCD test, the calculated specific capacitance of LC-05 is $281 \mathrm{~F} \mathrm{~g}^{-1}$ at a current density of $0.5 \mathrm{~A} \mathrm{~g}^{-1}$ (Fig. 6c). This demonstrates that ligninderived CNSs prepared by freeze-casting method has much better capacitive performance in $\mathrm{H}_{2} \mathrm{SO}_{4}$ electrolyte than many other carbon electrode materials obtained from lignin (145 F $\mathrm{g}^{-1}$ at $\left.0.5 \mathrm{~A} \mathrm{~g}^{-1}\right),{ }^{9}$ chicken eggshell $\left(250 \mathrm{~F} \mathrm{~g}^{-1} \text { at } 0.5 \mathrm{~A} \mathrm{~g}^{-1}\right)^{15}$ and cellulose $\left(165 \mathrm{~F} \mathrm{~g}^{-1}\right.$ at $\left.0.5 \mathrm{~A} \mathrm{~g}^{-1}\right){ }^{33}$ The high capacitance of LC05 is very likely to arise from its high surface area, high content of micropores and pseudocapacitance brought by the oxygen heteroatoms. ${ }^{15,28}$

Fig. 6c presents the specific capacitance of LC-05 at different charge-discharge current densities. For porous carbon, the specific capacitance usually shows gradual decrease as the current density increases because some pores may be blocked under higher current densities. ${ }^{33}$ When the current density increases from 0.5 to $20 \mathrm{~A} \mathrm{~g}^{-1}$, the specific capacitance of LC-05 shows a decrease from 281 to $153 \mathrm{~F} \mathrm{~g}^{-1}$, and a capacitance retention of $54 \%$ is achieved. The cycling stability of LC-05 electrode was evaluated by GCD tests at $1.0 \mathrm{~A} \mathrm{~g}^{-1}$ (Fig. 6d).

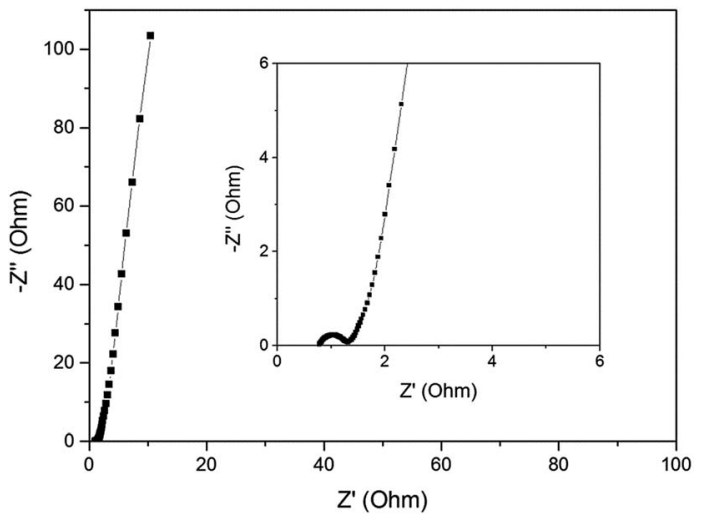

Fig. 7 Nyquist plot of LC-05 obtained from EIS test. Inset shows the magnified plot in the high-frequency region.

After 5000 test cycles, LC-05 showed capacitance retention of $91 \%$, indicating its good stability in acid electrolyte. Nyquist plot of LC-05 was obtained from EIS test, as shown in Fig. 7. LC05 possesses low ohmic resistance of $0.8 \Omega$ according to the value of the first intercept between the plot and real axis. The small semicircle appeared in the high-frequency region (inset of Fig. 7) is associated with the charge-transfer resistance which arises from the reversible faradaic reactions of the oxygencontaining groups. This semicircle also verifies the pseudocapacitance contribution from the oxygen heteroatoms. ${ }^{\mathbf{1 6}}$

To further investigate the capacitive properties for practical applications, the symmetric two-electrode systems were assembled to evaluate LC-05 electrodes in $1 \mathrm{M} \mathrm{H}_{2} \mathrm{SO}_{4}$ electrolyte. The GCD curves of LC-05 maintain symmetric triangle shapes at different current densities and have a small $I R$ drop (Fig. 8a), indicating good capacitive characteristics of LC-05 electrodes. According to the GCD test, the specific capacitance of LC-05 is calculated to be $182 \mathrm{~F} \mathrm{~g}^{-1}$ at a current density of
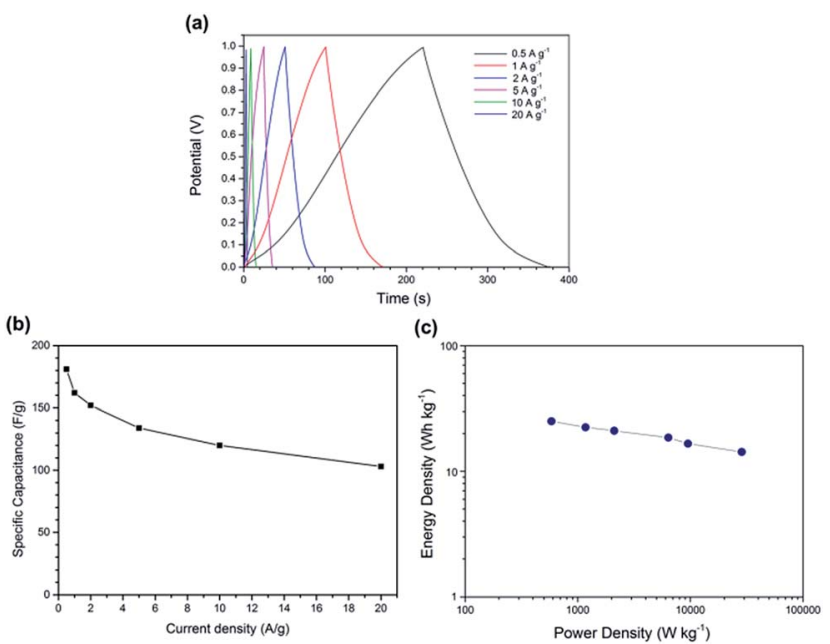

Fig. 8 Electrochemical performances of LC-05 electrode tested in a two-electrode system. (a) Galvanostatic charge-discharge curves of LC-05 at different current rates; (b) the rate performance of LC-05; (c) Ragone plot showing the energy density versus the power density. 
$0.5 \mathrm{~A} \mathrm{~g}^{-1}$ and maintains $103 \mathrm{~F} \mathrm{~g}^{-1}$ at a current density of $20 \mathrm{~A} \mathrm{~g}^{-1}$ (Fig. 8b). The energy density and power density of the two-electrode symmetric supercapacitor were calculated according to the results of GCD tests. ${ }^{34}$ The Ragone plot (Fig. 8c) shows the dependence of energy density upon the power density. The supercapacitor based on LC-05 shows an energy density of $25.1 \mathrm{~W} \mathrm{~h} \mathrm{~kg}^{-1}$ at a power density of $583 \mathrm{~W} \mathrm{~kg}^{-1}$ and an energy density of $14.3 \mathrm{~W} \mathrm{~h} \mathrm{~kg} \mathrm{~W}^{-1}$ at a power density of $28611 \mathrm{~W} \mathrm{~kg}^{-1}$, respectively. These results are higher or comparable to the reported values for many other electrochemical double layer capacitors based on the carbon materials derived from lecithin, ${ }^{35}$ sucrose ${ }^{36}$ and glucosamine ${ }^{37}$ in $\mathrm{H}_{2} \mathrm{SO}_{4}$ aqueous electrolyte.

\section{Conclusions}

In summary, CNSs are readily prepared by simply freeze-casting of lignin aqueous dispersion followed by direct carbonization at $900{ }^{\circ} \mathrm{C}$ without any activation agent. As the concentration of lignin dispersion increases, the size of the obtained ligninderived CNSs increases but their specific area decreases. WAXS and Raman studies indicate that the CNSs are partially graphitized during the carbonization process. The optimized CNSs (LC-05) show good conductivity $\left(2.5 \mathrm{~S} \mathrm{~cm}^{-1}\right)$ and excellent electrochemical performance as supercapacitor electrodes. The three-electrode supercapacitor based on LC-05 exhibits high capacitance of $281 \mathrm{~F} \mathrm{~g}^{-1}$ at $0.5 \mathrm{~A} \mathrm{~g}^{-1}$ current density in $\mathrm{H}_{2} \mathrm{SO}_{4}$ aqueous electrolyte, and good capacitance retention (91\%) after cycling tests for 5000 cycles. Moreover, the two-electrode symmetric supercapacitor based on LC-05 shows an energy density of $14.3 \mathrm{~W} \mathrm{~h} \mathrm{~kg}^{-1}$ at a power density of $28611 \mathrm{~W} \mathrm{~kg}^{-1}$. This method has the potential for preparation of CNSs from various water-soluble biomass. It may also be applied to prepare porous CNSs in combination with appropriate activating agents.

\section{Conflicts of interest}

There are no conflicts to declare.

\section{Acknowledgements}

This work was supported by the Fundamental Research Funds for the Central Universities (16D128105).

\section{References}

1 P. Simon and Y. Gogotsi, Nat. Mater., 2008, 7, 845-854.

2 L. L. Zhang and X. S. Zhao, Chem. Soc. Rev., 2009, 38, 25202531.

3 A. Divyashree and G. Hegde, Rsc Adv, 2015, 5, 88339-88352. 4 W. F. Deng, Y. M. Zhang, Y. M. Tan and M. Ma, J. Electroanal. Chem., 2017, 787, 103-109.

5 Q. Wang, J. Yan and Z. J. Fan, Energy Environ. Sci., 2016, 9, 729-762.

6 X. Zhang, H. T. Zhang, C. Li, K. Wang, X. Z. Sun and Y. W. Ma, Rsc Adv, 2014, 4, 45862-45884.
7 E. Raymundo-Pinero, M. Cadek and F. Beguin, Adv. Funct. Mater., 2009, 19, 1032-1039.

8 W. F. Deng, Y. J. Zhang, L. Yang, Y. M. Tan, M. Ma and Q. J. Xie, Rsc Adv, 2015, 5, 13046-13051.

9 Y. M. Tan, C. F. Xu, G. X. Chen, Z. H. Liu, M. Ma, Q. J. Xie, N. F. Zheng and S. Z. Yao, ACS Appl. Mater. Interfaces, 2013, 5, 2241-2248.

10 P. Hao, Z. H. Zhao, Y. H. Leng, J. Tian, Y. H. Sang, R. I. Boughton, C. P. Wong, H. Liu and B. Yang, Nano Energy, 2015, 15, 9-23.

11 W. L. Zhang, H. B. Lin, Z. Q. Lin, J. Yin, H. Y. Lu, D. C. Liu and M. Z. Zhao, Chemsuschem, 2015, 8, 2114-2122.

12 J. W. Jeon, L. B. Zhang, J. L. Lutkenhaus, D. D. Laskar, J. P. Lemmon, D. Choi, M. I. Nandasiri, A. Hashmi, J. Xu, R. K. Motkuri, C. A. Fernandez, J. Liu, M. P. Tucker, P. B. McGrail, B. Yang and S. K. Nune, Chemsuschem, 2015, 8, 428-432.

13 J. Cai, H. T. Niu, H. X. Wang, H. Shao, J. Fang, J. R. He, H. G. Xiong, C. J. Ma and T. Lin, J. Power Sources, 2016, 324, 302-308.

14 H. Wang, Z. W. Xu, A. Kohandehghan, Z. Li, K. Cui, X. H. Tan, T. J. Stephenson, C. K. King'ondu, C. M. B. Holt, B. C. Olsen, J. K. Tak, D. Harfield, A. O. Anyia and D. Mitlin, ACS Nano, 2013, 7, 5131-5141.

15 Z. Li, L. Zhang, B. S. Amirkhiz, X. H. Tan, Z. W. Xu, H. L. Wang, B. C. Olsen, C. M. B. Holt and D. Mitlin, Adv. Energy Mater., 2012, 2, 431-437.

16 Y. S. Yun, S. Y. Cho, J. Shim, B. H. Kim, S. J. Chang, S. J. Baek, Y. S. Huh, Y. Tak, Y. W. Park, S. Park and H. J. Jin, Adv. Mater., 2013, 25, 1993-1998.

17 A. Bello, N. Manyala, F. Barzegar, A. A. Khaleed, D. Y. Momodu and J. K. Dangbegnon, Rsc Adv, 2016, 6, 1800-1809.

18 A. J. Ragauskas, G. T. Beckham, M. J. Biddy, R. Chandra, F. Chen, M. F. Davis, B. H. Davison, R. A. Dixon, P. Gilna, M. Keller, P. Langan, A. K. Naskar, J. N. Saddler, T. J. Tschaplinski, G. A. Tuskan and C. E. Wyman, Science, 2014, 344, 1246843.

19 S. Sen, S. Patil and D. S. Argyropoulos, Green Chem., 2015, 17, 4862-4887.

20 W. J. Liu, H. Jiang and H. Q. Yu, Green Chem., 2015, 17, 48884907.

21 W. S. Liu, R. Zhou, H. L. S. Goh, S. Huang and X. H. Lu, ACS Appl. Mater. Interfaces, 2014, 6, 5810-5817.

22 W. S. Liu, R. Zhou, D. Zhou, G. G. Ding, J. M. Soah, C. Y. Yue and X. H. Lu, Carbon, 2015, 83, 188-197.

23 W. S. Liu, C. Y. Zhao, R. Zhou, D. Zhou, Z. L. Liu and X. H. Lu, Nanoscale, 2015, 7, 9919-9926.

24 S. P. J. M. Carrott and M. M. L. R. Carrott, Bioresour. Technol., 2007, 98, 2301-2312.

25 S. Deville, E. Saiz, R. K. Nalla and A. P. Tomsia, Science, 2006, 311, 515-518.

26 U. G. K. Wegst, H. Bai, E. Saiz, A. P. Tomsia and R. O. Ritchie, Nat. Mater., 2015, 14, 23-36.

27 W. Q. Tian, Q. M. Gao, Y. L. Tan, K. Yang, L. H. Zhu, C. X. Yang and H. Zhang, J. Mater. Chem. A, 2015, 3, 56565664. 
28 E. Raymundo-Pinero, F. Leroux and F. Beguin, Adv. Mater., 2006, 18, 1877-1882.

29 D. Puthusseri, V. Aravindan, S. Madhavi and S. Ogale, Energy Environ. Sci., 2014, 7, 728-735.

30 O. C. Compton, D. A. Dikin, K. W. Putz, L. C. Brinson and S. T. Nguyen, Adv. Mater., 2010, 22, 892-896.

31 L. Wei, M. Sevilla, A. B. Fuertes, R. Mokaya and G. Yushin, Adv. Energy Mater., 2011, 1, 356-361.

32 M. Toupin, D. Belanger, I. R. Hill and D. Quinn, J. Power Sources, 2005, 140, 203-210.
33 Y. J. Hu, X. Tong, H. Zhuo, L. X. Zhong, X. W. Peng, S. Wang and R. C. Sun, Rsc Adv, 2016, 6, 15788-15795.

34 W. Na, J. Jun, J. W. Park, G. Leea and J. Jang, J. Mater. Chem. A, 2017, 5, 17379-17387.

35 M. Demir, S. K. Saraswat and R. B. Gupta, Rsc Adv, 2017, 7, 42430-42442.

36 N. Subramanian and B. Viswanathan, Rsc Adv, 2015, 5, 63000-63011.

37 M. Sevilla, L. H. Yu, L. Zhao, C. O. Ania and M. M. Titiricic, ACS Sustainable Chem. Eng., 2014, 2, 1049-1055. 